
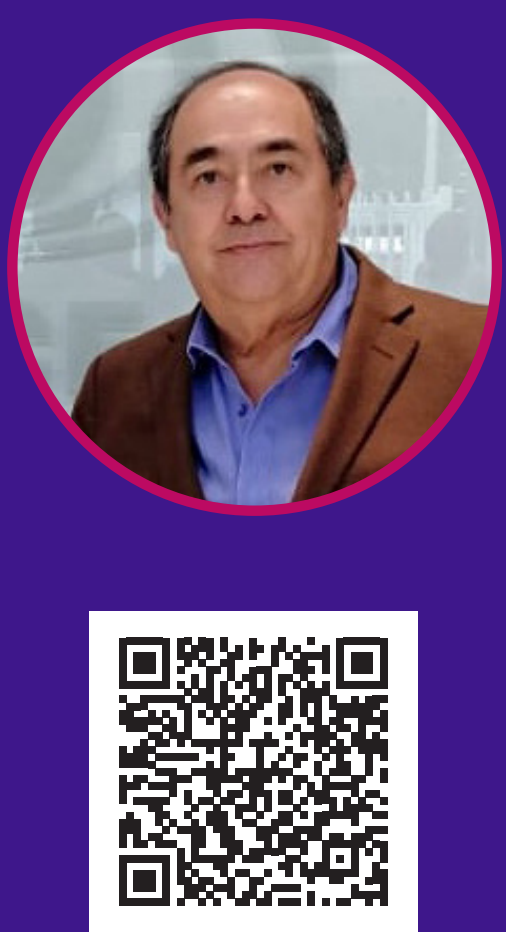

Videopresentación

\section{Estampas de la guerra de propaganda entre México y Estados Unidos en 1938}

\author{
Stamps of the propaganda war between Mexico and the United \\ States in 1938
}

\section{Dr. Miguel Ángel Sánchez de Armas}

Universidad Iberoamericana, México

iberomagsa@gmail.com Orcid: https://orcid.org/0000-0002-8108-9646

Recibido: 23 de septiembre de 2021. Aceptado: 26 de octubre de 2021.

Received: September 23rd, 2021. Accepted: October 26th, 2021.

Publicado: 30 de noviembre de 2021.

Published: November 30th, 2021.

cc $(1) \ominus$ Esta obra está bajo una licencia internacional Creative EY NC ND

Commons Atribución-NoComercial-SinDerivadas 4.0.

DOI: https://doi.org/10.21555/rpc.vi2.2444

Cómo citar: Sánchez de Armas, M. Ángel . (2021). Estampas de la guerra de propaganda entre México y Estados Unidos en 1938. RPC, (2), 133-144. https://doi.org/10.21555/rpc.vi2.2444

Revista Panamericana de Comunicación, Año 3, N. 2, julio-septiembre 2021, pp. 133-144

\section{RESUMEN}

La expropiación de la industria petrolera extranjera en marzo de 1938 fue un momento clave en la vida del México posrevolucionario. Por su carga simbólica propició la cohesión ideológica en el proceso de formación de una nueva identidad nacional anclada en los postulados de la Revolución y de la Constitución de 1917. En lo económico, echó los cimientos del modelo de desarrollo mexicano que persiste al día de hoy. Y en materia de política internacional, una de sus consecuencias fue intensa y prolongada guerra de propaganda entre México, EUA Inglaterra.

Palabras clave: México, Estados Unidos, Propaganda, Guerra.

\section{A B STRACT}

The expropriation of the foreign oil industry in March 1938 was a key moment in the life of post-revolutionary Mexico. Due to its symbolic charge, it fostered ideological cohesion in the process of forming a new national identity anchored in the postulates of the Revolution and the Constitution of 1917. In the economic sphere, it laid the foundations of the Mexican development model that persists to this day. And in terms of international politics, one of its consequences was an intense and prolonged propaganda war between Mexico, the United States, and England.

Keywords: Mexico, United States, propaganda, war 
a campaña desatada por las petroleras tuvo carácter mundial, pero fue especialmente importante en Estados Unidos. Dice Meyer que la tarea de la maquinaria propagandística se vio facilitada por el hecho de que los avances de la reforma agraria y el apoyo a los grupos obreros habían dado al régimen del presidente Cárdenas un tinte radical mucho antes de que ocurriera la expropiación. Aun cuando los prolegómenos de la guerra mundial en Europa y Asia desviaron la atención de los sucesos en México, las compañías estadounidenses y angloholandesas expropiadas pudieron difundir un mensaje antimexicano que llegó a inquietar a los mercados y a procupar a quienes no compartían los puntos de vista de las empresas ${ }^{1}$.

La estrategia de las petroleras fue abonar un clima de opinión pública favorable a una intervención de Washington para revertir la expropiación o para obligar al gobierno de México al pago inmediato del valor de las instalaciones en el monto que ellas mismas habían fijado.

La campaña desatada tanto en la prensa mexicana como en la de otros países nunca había sido igualada en su distorsión de los hechos. La prensa estadounidense examinó la presidencia de Lázaro Cárdenas a partir de sus propios prejuicios y sus informaciones raramente fueron nutridas por datos para comprender la dinámica de la sociedad mexicana o por el conocimiento de la historia de México ${ }^{2}$.

Desde luego viajaron a México enviados especiales, unos comprometidos con servir a sus lectores información equilibrada, como Anita Brenner, del New York Times Magazine; Betty Kirk, del Christian Science Monitor, y Adamatios Theophilus Polyzoides, de The Los Angeles Times y otros como el fiero Hal Burton, del Daily News, que parecía amanuense o de la Standard Oil o de los halcones del Departamento de Estado.

También arribaron creadores para consignar en prosa literaria el suceso. El británico Evelyn Waugh - "uno de los más brillantes escritores y una de las más desagradables personas del siglo veinte" ${ }^{3}$ estuvo entre

\footnotetext{
1 MEYER, 1968.

2 MORGAN, 1984.

3 MEYERS, 1989.
}

nosotros poco menos de dos meses en el otoño de 1938 y al amparo de la consigna de que el conocimiento superficial "es uno de los materiales de nuestro oficio", escribió Robbery Under Law4, 279 páginas de generalidades, lugares comunes, chismes y falsedades en el que México queda como palo de perico: sus gobernantes unos filocomunistas y el gobierno una máquina de robar. El viaje de Waugh fue financiado por Weetman Pearson, dueño de la petrolera El Águila, una de las empresas expropiadas, dato que el gran novelista convenientemente olvida consignar en su libraco.

...es difícil encontrar una crítica contemporánea con alguna referencia favorable a Robbery Under Law. En verdad es apenas un trabajo de propaganda cuyo tono oscila entre la histeria y el didactismo. Como ha señalado el biógrafo de Waugh, Martin Stannard, "con frecuencia recurre a la más vulgar diatriba" 5 .

Como dato adicional, además de la pluma alquilada a la casa Cowdray, el perfil político de Waugh -un hombre atormentado por el alcoholismo, la homosexualidad, el sobrepeso y las angustias religiosas- era el de un defensor de la moral de las clases dominantes y enemigo del gobierno representativo y de la educación popular.

Apoyó a Hitler cuando los nazis subieron al poder en 1933. Estaba impresionado con Mussolini y admiraba el fascismo por "su sencillez y honestidad". Juzgó la guerra en Abisinia como un conflicto entre la barbarie y la civilización y le tenía sin cuidado el uso de gas venenoso por parte de los italianos ${ }^{6}$.

\section{LA PRENSA}

La Standard Oil cuidó que sus voceros sirvieran puntualmente su versión de los hechos a los medios estadounidenses que se aprestaron a cubrir la noticia de la expropiación. Hasta muy avanzado el conflicto

\footnotetext{
4 WAUGH, 1999.

5 KOSTOPULOS, 2005

6 MEYERS, p. 123
} 
se privilegió la versión de la petrolera y con algunas excepciones, la prensa yanqui no buscó acercarse a fuentes mexicanas ${ }^{7}$.

La información que aparecía sobre la expropiación en la prensa gringa tenía su origen principalmente en Nueva York, Washington, Chicago y Los Ángeles, a partir de declaraciones de políticos, diplomáticos y hombres de negocios con datos proporcionados por la Standard Oil y demás empresas expropiadas. El periódico que cubrió el evento de manera más directa, constante y sistemática desde el lugar de los hechos fue The New York Times a través de su corresponsal, Frank L. Kluckhohn, y sus notas eran frecuentemente retomadas por otros medios ${ }^{8}$.

Un enfoque que propició la distorsión informativa fue el del "interés humano" sobre la situación de los trabajadores extranjeros. Si bien no se registraron casos de violencia física en contra de los ingenieros 0 de los empleados administrativos de las petroleras o de sus familias durante la toma de las instalaciones, algunos incidentes se sobredimensionaron con la intención de dar la impresión de que los trabajadores extranjeros de las petroleras eran hostigados.

El 22 de marzo de 1938, el New York Times publicó una nota de primera plana, firmada por Kluckhohn, que hablaba de "35 estadounidenses y británicos en éxodo" abandonando apresuradamente el país luego de "amenazas de muerte" ${ }^{9}$, sin precisar cuándo y cómo tales amenazas tuvieron lugar. El supuesto incidente fue reproducido por otros diarios y quizá haya contribuido a generar preocupación por la seguridad de aquellos ciudadanos.

Pero Morgan en los informes de la Embajada estadounidense el incidente se menciona como una fricción pasajera, y los propios involucrados poco después aclararon que nunca fueron objeto de amenazas y que el supuesto "enfrentamiento" había sido en realidad una discusión acerca de los tiempos y la forma en que algunas oficinas debían ser entregadas a los represen-

\footnotetext{
7 MORGAN, p. 76

8 Ibíd, p. 80

9 The New York Times, 22 de marzo de 1938.
}

tantes acreditados del sindicato ${ }^{10}$. Ni el New York Times ni Kluckhohn aclararon posteriormente la información.

Otro tema que alarmó a la opinión pública fue la venta de petróleo mexicano a las potencias del Eje después de la expropiación, difundido sin contextualizarlo en el marco del boicot que obligó al gobierno de Cárdenas a buscar urgentemente mercados en Europa y Asia.

Desde luego no se contrastó que empresas como la Standard Oil tenían años proveyendo de combustible a Japón, Alemania e Italia, con la justificación de que no había un estado de guerra que impidiera o condicionara el libre mercado con esas naciones. De esta manera se atizaba la sensación de que los mexicanos habían gravitado hacia la esfera de influencia del fascismo y se fortalecía la especie de que el régimen cardenista era profundamente antiyanqui.

Un ritornelo en la prensa del vecino país fue que México no tenía dinero para pagar el valor de las instalaciones expropiadas. En esto se insistía pese a que en el decreto expropiatorio se asentaba claramente que el pago se haría en un plazo de diez años y de que Cárdenas ofreció entregar a los acreedores el $60 \%$ de la producción petrolera como abono a la deuda, propuesta que fue rechazada ${ }^{11}$.

Al referirse a las consecuencias del decreto, un tema que se repite tiene que ver con el daño que las empresas extranjeras dijeron sufrir, sin mencionar que muchas concesiones habían sido obtenidas por medios ilegales o fraudulentos. Tampoco se daba espacio a las ganancias obtenidas durante los años de operación, el control absoluto sobre los volúmenes de producción, la evasión fiscal y las condiciones de los trabajadores. Tampoco las precarias condiciones de seguridad e higiene en que trabajaban los obreros mexicanos tuvieron gran valor informativo.

Por ejemplo, El Águila, creada en 1907 con un capital de 30 millones de pesos, tuvo ganancias netas por 164 millones 248 mil pesos entre 1911 y 1920. Es decir, en diez años recuperó más de cinco veces el capital invertido. $Y$ en cuanto al conjunto de las empresas

10 MORGAN, p. 203.

11 HERRING, 1937. 
extranjeras, de acuerdo a su propia contabilidad, el capital fijo al 31 de diciembre de 1936 era de 174,017,043 pesos, "mientras que el valor total del petróleo bruto extraído, por esas mismas fechas, se elevaba a la suma de 3,546,129,423 pesos, es decir, más de veinte veces el capital antes indicado"12.

Aunque la mayoría de los comentarios editoriales fueron desfavorables a México, se registran excepciones. El 10 de abril, Bertram D. Hulen en el New York Times se congratuló de que las relaciones oficiales entre México y Estados Unidos hubiesen salido airosas de la tormenta ocasionada por la expropiación. El presidente Lázaro Cárdenas, escribió, "ha asegurado públicamente que la situación política interna de México está bajo control, en tanto que su reiterado recononcimiento al presidente Roosevelt por su política parece haber acallado los temores latinoamericanos de que Estados Unidos sería muy severo ante una provocación mayor"13.

Adamatios Theophilus Polyzoides de The Los Angeles Times reportó que entre el pueblo mexicano privaba en realidad una fuerte corriente de simpatía hacia Estados Unidos, que Japón y Alemania eran muy poco admiradas, que los principales diarios coincidían en que México pagaría su deuda petrolera y que la expropiación era un asunto doméstico y no internacional ${ }^{14}$.

En el New York Times Magazine, Anita Brenner elogió los programas sociales del presidente Cárdenas que permitieron que muchos mexicanos "comprendieran por primera vez que eran ciudadanos con derechos" y dieron a los campesinos la primera esperanza de una vida segura y con comodidades.

Bruce Rae, del New York Times, entrevistó al presidente Cárdenas y destacó la invitación del primer mandatario a las empresas para buscar en forma conjunta un arreglo: "Las empresas extranjeras frecuentemente se quejan de que México carece de los recursos financieros suficientes para garantizar el pago de las grandes cantidades que habrá que liquidar" le dijo el presidente. "A ello sólo puedo responder que México po-

\footnotetext{
12 GARCÍA ROBLES, 1938.

13 The New York Times, 14 de abril de 1938.

14 MORGAN, p.87.
}

drá pagar en su totalidad esas sumas, quizá durante un periodo de varios años"15.

Uno de los artículos más solidarios con la causa mexicana apareció en la edición del 5 de agosto de la revista católica Commonweal, bajo la firma de Randall Pond. "No es muy útil recapitular todo lo que se ha dicho y hecho en el asunto del petróleo. Un estadounidense con el mínimo conocimiento sobre los métodos de las empresas petroleras en su propio país muy bien puede imaginar lo que una supuesta 'nación atrasada' debe sufrir cuando uno de los monopolios más poderosos del mundo empeña toda su fuerza para adquirir el 'oro negro'", escribión ${ }^{16}$.

Para Brígida Von Mentz, fueron The New York Times, el Washington Post, el Wall Street Journal, el New York Daily News y el Times Herald los campeones de la información antimexicana.

Desde abril de 1938 tres nefastas letras K aparecían firmando artículos en periódicos estadounidenses, relatando las acciones antiyanquis del gobierno mexicano, que según ellos embonaban perfectamente con los intereses del Tercer Reich, no sólo en nuestro país sino en toda América Latina. Ellos eran Betty Kirk, del Washington Post; Arthur Krok y Frank L. Kluckhohn del New York Times. Su línea común era aquella que vinculaba cualquier acto del Estado mexicano que afectase a los intereses estadounidenses en México con la bandera nazi ${ }^{17}$.

Contenidos y tendencias aparte, The New York Times fue el diario que con mayor constancia reportó la secuela informativa de la expropiación. Las notas del corresponsal Frank L. Kluckhohn están redactadas en prosa acelerada y eficaz, hábilmente aderezada con un tinte sensacionalista calculado para inquietar a los lectores preocupados por el avance de la "amenaza roja" y recelosos del "totalitarismo mexicano" en aquella era premacartista, sin preocuparse demasiado por profundizar en los hechos o por la debilidad de sus fuentes.

\footnotetext{
15 Ibíd, p. 88.

16 Ibíd, p. 89.

17 VON MENTZ, 1988.
} 
En un periodo de 43 días, del 19 de marzo al 30 de abril de 1938, el NYT publicó 15 notas de primera plana sobre el conflicto petrolero con México, 14 de ellas firmadas por Kluckhohn. La orientación de sus notas, preñadas de editorializaciones, traduce su visión de México y de sus habitantes, misma que trasminó a su libro The Mexican Challenge, publicado poco después de su expulsión del país.

México, según Kluckhohn, era "la única nación en el mundo alabada unánimemente por los estalinistas, los trotskistas, los hitlerianos y un reducido grupo de liberales estadounidenses", y en donde se construía, "quizá inconscientemente", un sistema de socialismo de Estado ${ }^{18}$.

En un intento por crear una sociedad materialista, dominada por el Estado, al sur del Río Grande se genera un sistema de vida y de gobierno disonante con y probablemente opuesto al sistema de vida y gobierno de Estados Unidos. Algunos de los hechos que demuestran esto son: la eliminación en México de la libertad sindical mediante el control conjunto de los trabajadores organizados por parte de dirigentes obreros y el Estado; la campaña para insertar al control oficial a las cuatro quintas partes de la población del campo; el control de los medios de información y el fracaso del intento de construir un sistema democrático a través de elecciones libres y poderes legislativo y judicial independientes ${ }^{19}$.

\section{REVISTAS}

La cobertura informativa de la expropiación en revistas yanquis fue mucho más superficial y distorsionada que la de los diarios. Time, The Atlantic Monthly, American Mercury, Harper's Monthly Magazine, Collier's y Reader's Digest, no hablaron de la disputa petrolera antes del decreto de marzo de 1938, y cuando la expropiación llegó a sus páginas tuvo el mismo tono que la de los diarios: ausencia de contexto histórico, parcialidad hacia las petroleras, pocas menciones a la situación laboral, desestimación de las condiciones en que obtu-

\footnotetext{
18 KLUCKHOHN, 1939.
}

19 Ibíd, p. 187. vieron las concesiones y su comportamiento en el país, y ninguna alusión a la evasión fiscal o al traslado de capitales fuera de México. En su primer reportaje sobre la expropiación, la revista Time utiliza adjetivos, verbos y participios que no dejan bien parada la imagen del evento. En el primer párrafo de la nota se lee:

Después de exigir a gritos un aumento salarial durante dos años (fijado en $\$ 7,300,000$ por la Junta Federal del Trabajo el pasado diciembre) que las 17 petroleras extranjeras establecidas en México insisten en "no poder pagar", una turba de obreros petroleros prietos y desaseados invadió [los campos petroleros] un día la semana pasada apoderándose de torres, refinerías, vías férreas y autos tanque. Peones jubilosos [...] invadieron las oficinas, los almacenes y las tiendas. En el muelle de carga de Tampico, treparon en tres tanqueros británicos y los reclamaron para los 18 mil trabajadores petroleros de México ${ }^{20}$.

La excepción fueron las revistas eclesiásticas y las de izquierda. Commonweal, de la iglesia católica, y Christian Century, de la protestante, dieron espacio a la versión mexicana de los hechos en sus informaciones sobre la expropiación, e intentaron explicar a sus lectores el contexto histórico y legal en que esta se dio.

"Es importante recordar que México está enfrentando el difícil problema de recuperar para su pueblo una parte de la riqueza nacional que tan generosamente Díaz entregó a los extranjeros”, publicó Christian Century en su número del 30 de marzo de 1938.

The New Republic abordó la expropiación a partir del antecedente de la Constitución de 1917 y explicó que las petroleras habían explotado los recursos mexicanos en la tradicional manera del imperialismo empresarial. "El grito de guerra del actual régimen mexicano, México para los mexicanos, tiene una gran justificación moral”, editorializó la revista, y justificó la venta de petróleo mexicano a las potencias del eje como única salida al producto después del boicot de las petroleras estadounidenses e inglesas.

20 Time, 25 de abril de 1938. 
The Nation mantuvo una línea editorial coincidente con el punto de vista de los liberales mexicanos. En muchos artículos se esforzó por dar información objetiva, como cuando analizó el diferendo sobre el valor de las propiedades expropiadas entre las empresas y el gobierno de México y abogó para que se encontrara el camino a un esquema de cooperación con México en la industria petrolera, a partir de la aceptación de que este país era el propietario del producto y seguiría siéndolo.

Quizá el análisis más completo y perspicaz de la expropiación fue el del Harper's Monthly Magazine, firmado por el historiador Hubert Herring, con el título "Cárdenas de México", en donde se explica el contexto histórico del cardenismo y la complejidad de la expropiación petrolera.

Mención aparte merece la revista liberal The Atlantic Monthly, que vendió su prestigio a cambio de treinta barriles de petróleo. Esto se aborda más adelante.

\section{LA MANO QUE MUEVE LA PLUMA}

Para derrocar al presidente expoliador, en los corporativos de la Standard y de El Águila las esperanzas estaban puestas en el general Saturnino Cedillo, quien desconoció a Cárdenas y condenó la expropiación. Para facilitar este objetivo, además de prensa, radio y rumores, se distribuyeron folletos en universidades, clubes, organizaciones sociales y en conferencias con el pie de imprenta de la Standard y títulos tan sugerentes como:

» ¿Confiscación o Expropiación?

» Justicia denegada, protección diplomática, promesas vacías, inversiones y comercio.

» El fino arte de la exacción.

"Las expropiaciones mexicanas en el derecho internacional.

» La respuesta a México.

» La solución a la confiscación mexicana.

» Tomaron lo que quisieron.
No menos escandalosos y denigrantes fueron los titulares de algunos prestigiados e influyentes diarios:

» Hitler gobierna México.

» Pacto secreto revelado.

» La Doctrina Monroe violada.

» 1,500 oficiales del ejército alemán mandan en el ejército, en las escuelas y en las minas.

»Arsenales secretos descubiertos.

»Un oleoducto a través del Istmo de Tehuantepec para dar a los japoneses una base naval en la costa occidental.

» Se acusa a Cárdenas de favorecer el dominio nazi en México: Virtualmente convertido en dictador, amolda todas las políticas, crea y destruye ayudas. Al principio favorable a los comunistas, los abandonará después del pacto concertado en una reunión con la delegación italo-nazi-japonesa.

» Representantes rojos burlados ${ }^{21}$.

Estas ideas encontraron eco en editoriales publicados en todo Estados Unidos, lo mismo en diarios sensacionalistas que en periódicos y revistas reputados, como el New York Times, el Washington Post, el Wall Street Journal o la revista Foreign Affairs. La cadena de Hearst se singularizó por lo virulento y constante de sus ataques a México. Esta campaña de prensa se replicó en Inglaterra y en otros países europeos.

El conflicto avivó la belicosidad de un Departamento de Estado amamantado en la doctrina del gran garrote parida en 1902 por el presidente Theodore "Teddy" Roosevelt. Pero según el embajador de Estados Unidos, Josephus Daniels, en esta guerra de nervios instigada desde las oficinas de las petroleras en Londres y

21 LÓPEZ GONZÁLEZ, 2002. 
Nueva York, "dos funcionarios públicos conservaron la cabeza mientras muchos otros la perdían a su alrededor: Franklin Roosevelt en la Casa Blanca, autor de la doctrina del buen vecino, y Josephus Daniels, el delegado de esa doctrina en la República Mexicana"22.

Según la investigación de Meyer, periodistas profesionales fueron comisionados para viajar a México y escribir reportajes negativos. Aparentemente diarios mexicanos anticardenistas fueron subvencionados. Se editaron folletos en español e inglés que atacaban la validez jurídica, económica y ética de la medida ${ }^{23}$.

La estrategia fue dar una "orientación adecuada" a las noticias sobre el conflicto petrolero. Tal "orientación" se tradujo, en memoria de Jesús Silva Herzog, en una empresa de "inquina inaudita". México era presentado con los colores más sombríos. "Éramos", escribió, "un país de ladrones, nos habíamos robado el petróleo y estábamos incapacitados para pagar los bienes de que nos habíamos apropiado, y no sólo no podíamos pagar, sino que además no queríamos pagar"24. La Standard financió por varios años una hoja quincenal gratuita, Looking at Mexico, que reproducía noticias aparecidas en la prensa extranjera criticando la expropiación y a Cárdenas. Agentes de las empresas cabildearon con los directores de los grandes rotativos estadounidenses para convencerlos de tomar su partido en la campaña contra el expropiador ${ }^{25}$.

El resultado no se hizo esperar. La inclinación roja del gobierno mexicano azuzó a demócratas y republicanos para exigir un cambio en la política del buen vecino y en general en los centros empresariales creció el recelo ante el "radicalismo mexicano". La jerarquía católica gringa, irritada desde el conflicto cristero, también se sumó al coro que pedía a Roosevelt mano de

\footnotetext{
22 DANIELS, 1947. Sobre la evidente simpatía que el Embajador profesaba por Cárdenas y su programa político, derivada de sus raíces liberales, Knight ha hecho la perspicaz observación de que "sin duda también quería limpiar su conciencia de la mancha de la ocupación de Veracruz" en 1914 cuando estuvo al frente de la Secretaría de Marina. Cfr. KNIGHT, 1992.

23 MEYER, p. 23

24 SILVA HERZOG, 1933.

25 MEYER, p. 26. Dice que William Miller, miembro de la Cleveland Press, informó a Daniels que David Henshaw, de la Standard, estaba entrevistando a los directores de los principales diarios con tal fin.
}

hierro en el trato con México ${ }^{26}$. "En periódicos de Estados Unidos se hablaba de que pronto estallaría, o había estallado ya, una revolución que daría al traste con el gobierno del general Lázaro Cárdenas”27.

En México las empresas recurrieron a la prensa de oposición para dar resonancia a sus reclamos y provocar intranquilidad entre el pueblo y la clase política. La posibilidad de una represalia armada habría estado más o menos en la mente de todos y el triunvirato estadounidense-inglés-holandés, no dejó pasar la oportunidad de echar gasolina a esa hoguera que muchos deseaban ver fuera de control.

En la Ciudad de México apareció El Economista, publicación auspiciada por los corporativos expropiados, "dirigida seguramente por un mexicano equivocado y de la cual fueron redactores mexicanos equivocados también", según el indignado parecer de Silva Herzog 28 .

Un "Instituto de Estudios Económicos y Sociales de México" produjo una larga serie de artículos en contra de la expropiación y de la política cardenista en genera ${ }^{29}$ que aparecieron en Hoy, publicación que también publicó críticas de Luis Cabrera y M. H. Güereña.

La ofensiva al interior de México operó en dos niveles. Uno dirigido principalmente a ciudadanos bien o medianamente informados que entenderían el mensaje de los reportajes de Hoy o los argumentos de EI Economista y de Looking at Mexico y otro que tuvo en mente al sector popular, analfabeta y desinformado. En ambos casos se buscó explotar la vulnerabilidad social provocada por una economía en crisis y la zozobra a flor de piel por la memoria entonces fresca de la toma de Veracruz, la Revolución, la Decena Trágica, los alzamientos de caudillos o la Guerra Cristera.

\footnotetext{
26 Ibíd, p. 29

27 SILVA HERZOG, p. 65.

28 Ibíd, p. 70. Esta opinión la comparte Lorenzo Meyer: "A raíz de la expropiación surgió una revista mensual, El Economista, que no fue otra cosa que un órgano propagandista de las empresas petroleras". MEYER, 1968.

29 "La deuda de México es de 8,584,873,000 pesos, en tanto los ingresos ascienden a 350,000,000, de donde se desprende que estamos en bancarrota e impedidos de cumplir con nuestros compromisos". Citado en McCONNELL, 1939.
} 
En general, la prensa de oposición, financiada o no por las petroleras, insistió en sus consignas de combatir el comunismo cardenista traducido en la educación socialista, el reparto de tierras, los ejidos, las huelgas, la militancia roja de los líderes obreros -Lombardo Toledano en primerísimo lugar- la manía expropiatoria y la solidaridad con las victimas del fascismo.

Cárdenas se vio obligado a responder a la ola de rumores que creaban confusión política, desorientaban al pueblo y auguraban próximas catástrofes, con su consecuente impacto en la economía.

\section{THE ATLANTIC}

En junio de 1938, tres meses después de la expropiación, comenzó a distribuirse en Estados Unidos, bajo el sello de The Atlantic (la emblemática revista liberal fundada en 1857 por Ralph Waldo Emerson, Henry Wadsworth Longfellow, James Russell Lowell y Oliver Wendell Holmes), una singular publicación: The Atlantic Presents. Trouble Below the Border. Why the Mexican Struggle is Important to You ${ }^{30}$.

No hay duda alguna de que la Standard Oil financió la edición del panfleto. Además del pie de imprenta, tenemos el testimonio del embajador Daniels. Un alto funcionario del Departamento de Estado le reveló que en 1938 The Atlantic atravesaba por graves dificultades económicas y que Edward Weeks, el noveno editor de la revista, negoció con la Standard Oil la edición de un folleto que sirviera a los propósitos de propaganda de la petrolera ${ }^{31}$.

Otra revista liberal, The Nation (que acusó a la prensa estadounidense de cubrir la expropiación "con la misma eficacia de un Estado totalitario"), analizó el caso de The Atlantic Presents... y descubrió: uno, que ese impreso no fue enviado a los suscriptores normales de la revista; y dos, que utilizó para su distribución las listas de correos de un "Comité de relaciones mexicanas", agrupación supuestamente ciudadana que en realidad funcionaba como un frente de propaganda de la

30 The Atlantic presenta. Problemas bajo la frontera. Por qué el conflicto en México es importante para usted.

31 DANIELS, p. 203
Standard Oil. The Nation contactó a The Atlantic Monthly, empresa editora del panfleto:

Cuando hablamos por teléfono a Boston con Donald Snyder, del Atlantic Monthly, aceptó desde luego que el suplemento había sido vendido en lote a "numerosas organizaciones gremiales". Dijo no recordar si entre estas figuraban las compañías petroleras, aunque no descartó tal posibilidad. Así, una publicación que se presenta como fuente de información indispensable sobre la crisis mexicana depende principalmente de la buena voluntad del más activo enemigo de México $^{32}$.

Sólo The Nation se refirió tan directamente a la vileza del Atlantic Monthly, y aunque otras publicaciones tomaron nota, no hubo esfuerzos adicionales para ahondar en el asunto.

No hay duda de que tal como dijo en su momento el embajador Daniels, The Atlantic arrendó su nombre a la Standard Oil.

Es interesante el juicio del Embajador sobre el asunto. Sin sutilezas diplomáticas deja traslucir su indignación por este suceso en el que la revista perdió la virtud.

Lo más bajo a que llegó la propaganda en contra de las políticas [de México] y de sus funcionarios fue la de la revista Atlantic Monthly, una de mis favoritas a lo largo de mi vida hasta que se degradó entregándose a los intereses petroleros. Cayó de las alturas al más profundo abismo y se ganó el desprecio de todos quienes vieron que una revista que durante mucho tiempo gozó de la confianza popular había perdido la decencia, como lo fue, cuando abrazó la campaña de las compañías de petróleo que deseaban que Estados Unidos le declarara la guerra a México ${ }^{33}$.

\footnotetext{
MORGAN, p. 142.
}

DANIELS, p. 206. 
En términos semejantes se expresó Jesús Silva Herzog, para quien la publicación trataba de crear una psicosis en el pueblo estadounidense a fin de que apoyara la petición hecha en repetidas ocasiones por los representantes de las empresas ante el Departamento de Estado para que se declarara la guerra a México ${ }^{34}$.

The Atlantic Presents... es una revista de 64 páginas tamaño carta, con pie de imprenta de The Atlantic Monthly Company, 10 Ferry Street, Concord, New Hampshire. El registro la identifica como volumen 1, número 1 , como si fuese un nuevo producto de la casa editorial, pero fue una edición única, con precio de portada de 25 centavos, equivalente al salario mínimo de una hora establecido por el gobierno de Roosevelt: no era una publicación destinada a las clases populares de un país en medio de una depresión.

En la portada, sobre un fondo rojo y con un título de gran puntaje que grita "Problemas abajo de la frontera", un jornalero mira desde su desesperanza y pobreza ${ }^{35}$ mientras una cabeza secundaria anuncia "información indispensable sobre la crisis latinoamericana" y seis balazos dan cuenta de la temática interior: 1$)$ tierra, 2) minería, 3) ferrocarriles, 4) petróleo, 5) utilidades y 6) inversiones. Las seis fosas del peligro mexicano.

En su contenido, The Atlantic Presents..., ofrece una colección de artículos y cartones recopilados de diversas publicaciones (ausentes las firmas habituales de la casa) con un mensaje común: los mexicanos son traicioneros, ladrones, despilfarradores, ingratos, desleales, tontos y negros ${ }^{36}$. Su capacidad de razonamiento es inferior a la de otras razas por la dieta de maíz con la que históricamente se han alimentado. La flojera e indolencia son características de la raza. Es una marabunta incapaz de gobernarse a sí misma que debe ser colocada bajo la tutela de una raza superior. México como país carece de credibilidad. No tiene ni los recursos ni la

\footnotetext{
34 SILVA HERZOG, p. 71.

35 Un toque de malicia propagandística fue acreditar la foto a la "cortesía de la Oficina de Turismo del Gobierno de México": una admisión de culpa del mismo gobierno criticado.

36 Representar a los mexicanos como negros es evidencia de la mentalidad racista sajona: toda persona de piel oscura pertenece a una raza inferior que debe ser tutelada por la superior, es decir, la blanca.
}

voluntad para pagar los bienes petroleros que robó bajo el disfraz de una "expropiación".

\section{MÉXICO EN EL BANQUILLO DE LOS ACUSADOS}

Un año después, a mediados de 1939, apareció el libro Mexico at the Bar of Public Opinion. A Survey of Editorial Opinions of Newspapers in the Western Hemisphere ${ }^{37}$ de Burt M. McConnell, concebido para reforzar los prejuicios de un público que sin duda vería con preocupación cómo México navegaba "hacia el comunismo" bajo la conducción del general Cárdenas. Su propósito fue potenciar la exigencia de una acción "decidida" de Washington para meter en cintura a quienes se habían "robado" las empresas petroleras estadounidenses en marzo de 1938.

Es un libro de 320 páginas con una compilación comentada de las posturas editoriales sobre la expropiación petrolera tomada de 258 periódicos de 45 estados de los EUA y el Distrito de Columbia (no se incluyeron Arkansas, Hawái, Nevada, Dakota del Norte y Wyoming), y de 13 periódicos de seis países del continente, incluyendo a México. Cita además 18 revistas y nueve agencias cablegráficas.

Esta empresa —que incluso para las modernas técnicas de análisis y herramientas informáticas se antoja formidable ${ }^{38}$ - no pudo ser sin recursos económicos como sólo podrían proporcionar organizaciones con "bolsillos muy profundos" por citar a Silva Herzog.

La publicación incorpora editoriales que coinciden con el punto de vista de las petroleras — nada de opiniones de los Commonweal o de los The Nation-y se presenta como portadora del sentir "verdadero" de la opinión pública hacia México.

\footnotetext{
37 México ante el tribunal de la opinión pública. Una encuesta de opiniones editoriales en periódicos del hemisferio occidental. McConnell, fue integrante de la dirección del Literary Digest durante diez años, de 1919 a 1929, una de las más influyentes publicaciones de la época, con más de dos millones de suscriptores — cifra astronómica si recordamos que el país atravesaba por la crisis que desembocó en la gran depresión-y circulación en miles de escuelas primarias en donde era material didáctico para acercar a los niños a la cultura de la información. Fue en el Editorial Digest donde nacieron las encuestas de opinión pública.
}

38 En 1938 se publicaban 13,220 periódicos en los estados y territorios de Estados Unidos. Cfr. AYERS. 
McConnell asegura que las opiniones recogidas son las "observaciones independientes y no prejuiciadas" de periodistas profesionales. Y sugiere que si "la experiencia del pasado" tiene algún significado, "estas críticas editoriales sin sombra de duda señalan el derrotero que nuestro gobierno debiera tomar para resolver sus problemas con México”. ¿A qué se refiere McConneII? No se requieren poderes adivinatorios para llegar a la única conclusión posible: la ocupación de Veracruz en abril de 1914.

McConnell subraya la importancia de un estudio social y político basado en la revisión y compendio de fuentes editoriales que tomen en cuenta que México, al confiscar propiedades estadounidenses, "afectó a los accionistas de 1,750 empresas que tienen inversiones directas por cinco mil millones de dólares [de 1938] en América Latina, y que se ven en apuros por el peligro de que el nefando ejemplo de México cunda entre otros países".

El libro se divide en once capítulos con cinco apéndices e incluye 40 cartones referidos todos a la confiscación de la industria petrolera. Comienza cada capítulo un argumento central y a continuación lo justifica con las opiniones de articulistas, editorialistas, columnistas y opinadores para convencer que algo turbio ocurre en el país del sur y llegar a la conclusión de que el uso de la fuerza para recuperar las propiedades expropiadas es el camino aceptable y quizá necesario.

El libro está ilustrado con cartones en donde se atacan las políticas cardenistas y se ridiculiza la persona del General. Se busca decir al lector que el presidente de México es un "indio" inculto, abusivo e irresponsable como todos los mexicanos.

Pero no tarda en aparecer la cola del felino agazapado tras la autoría: en la cuarta línea del segundo párrafo de la presentación, McConnell ${ }^{39}$ candorosa - o cínicamente-revela que acudió en busca de ayuda a la Standard Oil y que esta financió el proyecto. En la

39 He aquí a un personaje interesante y misterioso. Además de su paso por el Literary Digest, es coautor de un libro ilustrado sobre la Casa Blanca y de narraciones cortas de aviación y aventuras en revistas de la época (The American Museum Journal, The Saturday Evening Post, Air Stories y Northwest Romances). En 1915, según una nota del New York Times, era secretario del famoso escritor y explorador ártico canadiense de ascendencia islándica Vilhjámur Stefánsson. The New York Times, 16 de febrero de 1915. página legal se puede leer: Copyright, 1939, by Standard Oil Company (N. J.).

\section{LA VOZ DEL AMO}

La Standard Oil utilizó su revista The Lamp como otro ariete en la campaña antimexicana o, para ser precisos, anticardenista. En opinión del embajador Daniels, The Lamp era un órgano de propaganda para animar el odio antimexicano y obligar al Tío Sam a mandar a sus muchachos al sur de la frontera y no precisamente de vacaciones.

No se limitó a propalar pestes sobre la expropiación, recuerda en sus memorias don Josephus; también perfeccionó el arte de inflar cualquier incidente que manchara la imagen de México y contribuyera a atemorizar a posibles inversionistas e incesantemente pidió a Washington suspender las compras de plata para quebrar al tesoro mexicano ${ }^{40}$.

Con malicia jurídica, The Lamp intenta convencer a sus lectores de que las empresas fueron despojadas ilegalmente. Desde luego nunca habló del fondo legal de la expropiación: el desacato de las empresas a una decisión de la Suprema Corte de Justicia mexicana. Se trataba de azuzar a los lectores para presionar a su gobierno en contra del vecino del sur. Pero una vez que las empresas vieron que poco o nada lograban con sus campañas de propaganda negra, recurrieron a la estrategia de intentar quebrar la economía mexicana.

\section{DE ROJOS, NAZIS Y PRECIPIOS COMUNISTAS}

Del 23 al 28 de mayo de 1940, el Daily News ${ }^{41}$, un tabloide neoyorquino inspirado en el amarillista Daily Mirror de Londres, publicó una serie sobre México firmada por su enviado especial Hal Burton, un periodista muy conocido, alguna vez candidato al Pulitzer, más reaccionario que James Polk y más antimexicano que Jack London y Frank Kluckhohn juntos.

\footnotetext{
40 DANIELS, p. 248.

41 Quinto diario en circulación en Estados Unidos, con un tiraje de 632, 595 ejemplares en junio de 2009.
} 
Recorrió en auto, tren y avión ocho mil kilómetros en México durante cinco semanas y después de tan exhaustiva inspección llegó a la conclusión de que la nave mexicana iba a pique, condenada al naufragio por una revolución derechista a la vuelta de la esquina, por el trabajo de los quintacolumnistas, por la fuga de capitales, por el creciente desasosiego de la población urbana y rural o por todo esto al mismo tiempo.

Pardeaba el régimen cardenista y la elección presidencial se anticipaba reñida. Las petroleras no perdían la esperanza de doblegar al gobierno y recuperar más que sus bienes el prestigio perdido en la expropiación. Había optimismo de que el nuevo presidente fuese proempresarial y más maleable que Cárdenas. Los artículos de Burton desde la Ciudad de México, Tampico, Orizaba y Mérida, están escritos para dar al gringo medio la idea de que en un mundo peligroso, "en donde Europa está en llamas por un lado y Asia arde por el otro", aumentaba la amenaza al sur de la frontera ${ }^{42}$.

La serie fue reimpresa en una edición sin pie de imprenta, sobre papel periódico y en el tamaño tabloide original, para ser distribuida masivamente como parte de la ofensiva de propaganda de las petroleras contra el gobierno de México ${ }^{43}$.

Los artículos van in crescendo a partir del jueves 23 de mayo, cuando desde la ciudad de México, Burton escribe que a nuestro país se le ve maduro para una insurrección derechista:

Sus 20 millones de habitantes esperan inquietos la señal. Una señal del Tío Sam después de las elecciones presidenciales del 7 de julio y el gobierno izquierdista del presidente Lázaro Cárdenas, expropiador de propiedades estadounidenses y británicas con valor de 450 millones de dólares, se enfrentará a un golpe de Estado ${ }^{44}$.

42 Daily News, "The Mexican Mystery", viernes 25 de abril de 1940.

43 Consultado en marzo de 2008 en el fondo de publicaciones del Teresa Lozano Long Institute of Latin American Studies de la Universidad de Texas en Austin.

44 Daily News, "Mexico Seen Ripe for Rightist Revolt", 23 de mayo de 1940.

Revista Panamericana de Comunicación

Año 3 No. 2 Julio - Diciembre 2021
Burton entrevistó al general Juan Andreu Almazán, candidato presidencial de la derecha, quien le dijo que el ejército debía garantizar las elecciones, pero que de darse un fraude, "el pueblo sabrá cómo responder". En opinión del periodista, este candidato — quien le confió su parecer de que México debía permanecer leal a Estados Unidos y que esta nación debía ser amiga y protectora de México - es quien podría enfrentar "a los rojos y a los nazis".

El viernes 24, también desde la capital de la República, Burton reportó que la quinta columna mexicana cerraba filas y comenzaba a volver la vista al norte. "Alemania tiene en tierra mexicana a 200 muy activos agentes, más que durante la [primera] guerra mundial, cuando Carranza mantuvo una dudosa neutralidad", escribe. "Rusia también está activa entre bambalinas. Los comunistas vernáculos y compañeros de viaje son sus recaderos. Algunos de los agentes españoles antifranquistas se encargan de las demás tareas, mientras Japón se mantiene al margen, distribuyendo discretos donativos en forma de 'inversiones'" 45

En la entrega del sábado 25 fechada en Tampico, Burton encuentra que México ha descubierto que la confiscación petrolera fue un gigantesco fracaso. "La operación gubernamental de los 450 millones de dólares en pozos y refinerías expropiados a empresas estadounidenses, británicas y holandesas ha fracasado. De mala gana, pero finalmente, el país se enfrenta a esta realidad" 46 .

Y el lunes 27 Burton notifica desde Orizaba que los capitales de inversión huyen del puño de hierro del sindicalismo mexicano.

El ganso de los huevos de oro se fríe en el sartén de los trabajadores en México. Inversiones extranjeras que alguna vez llegaron a 2,500 millones de dólares se han reducido a la mitad mientras un millón de desarrapados se impone a jueces timoratos y a un presidente condescendiente $^{47}$.

45 Daily News, "5th Column in Mexico Turns Its Face North", 24 de mayo de 1940.

46 Daily News, "Mexico Finds Oil Grab Was Gigantic Flop", 25 de mayo de 1940.

47 Daily News, "Capital Flees Iron Squeeze of Mexican Labor", 27 de mayo de 1940. 
El martes 28, Burton termina su serie con un reportaje fechado en Mérida en donde da la noticia de que los peones mexicanos por fin descubrieron que Cárdenas no es Santa Claus: "El peón mexicano ha sido emancipado al estilo soviético. Antes trabajaba en una hacienda y recibía sueldos de hambre. Hoy trabaja para el gobierno y frecuentemente no recibe salario" 48

Para disipar cualquier duda sobre la "objetividad" con la que el Daily News reportó sobre la situación de México, el sábado 25 de mayo publicó un editorial con el título "El misterio mexicano" en donde primero expresa su desconcierto por la política de mano blanda - o la ausencia de política - con la que el gobierno del New Deal trataba a México, país a quien toleraba la venta de petróleo a las naciones del Eje y al que subsidiaba con la compra de plata a precio inflado no obstante haber confiscado propiedades estadounidenses.

48 Daily News, "Peons Find Cardenas is no Santa Claus", 28 de mayo de 1940
Zorrunamente, el diario se hace eco de rumores "seguramente infundados" pero que por ahí circulaban, de que el trato de súper buen vecino dispensado a México formaba parte de un pago de facturas de campaña por la aportación de medio millón de dólares del sindicato minero a la campaña de Roosevelt en 1936, acordado por el dirigente John L. Lewis "quien es muy cercano al dirigente obrero mexicano Vicente Lombardo Toledano"49.

"México [cierra el editorial] ya se encuentra en el precipicio del comunismo total, gracias a que su gobierno ha tomado muchas enseñanzas de su huésped de honor León Trotsky [...] Y es de imaginar que México pueda ser utilizado como una plataforma de lanzamiento de una invasión a Estados Unidos" ${ }^{\prime 5}$. \

49 Daily News, "The Mexican Mystery", 25 de mayo de 1940

50 Ibíd

\section{REFERENCIAS}

» AYERS, N. W.: Directorio de Periódicos, Biblioteca del Congreso, Washington. Consultado en diciembre de 2006.

» BURTON, Hal. A series of Special Articles on Mexico. Reprinted from The New York Daily News, Biblioteca del Instituto de Estudios Latinoamericanos Teresa Lozano Long, Sección de Fondos Especiales, Universidad de Texas en Austin (sin pie de imprenta o fecha de reimpresión).

» DANIELS, Josephus (1947). Shirt - Sleeve Diplomat. Ambassador to Mexico 1933-1942. Chapel Hill, The University of North Carolina Press.

» GARCÍA ROBLES, Alfonso (1938). La cuestión del petróleo en México y el derecho internacional", conferencia dictada en la "Salle Pulchri Studio", La Haya, 20 de agosto de 1938.

» HERRING, Hubert Clinton (1937). "The Unconquerable Mexican”, Harper's Monthly Magazine, June, vol. 175, pp. 46 - 56.

» KLUCKHOHN, Frank L. (1939). The Mexican Challenge. New York, Doubleday, Doran \& Company, Inc.

» KNIGHT, Alan: "The Politics of Expropriation”, en BROWN, Jonathan C. \& KNIGHT, Allan (editors): The Mexican Petroleum Industry in the Twentieth Century, University of Texas Press, Austin, 1992.

» KOSTOPULOS, Dan S. (2005). "Mexico Imagined: Robbery Under Law and the Lessons of Mexican Travel". Waugh Without End. New Trends in Evelyn Waugh Studies, Villar Flor, Carlos \& Murray Davis, Robert (eds). Bern: Die Deutsche Bibliothek.
» LÓPEZ GONZÁLEZ, Rafael (2002). Departamento Autónomo de Prensa y Publicidad (dapp). La experiencia del Estado cardenista en políticas estatales de comunicación, 1937 - 1939, tesis de licenciatura (inédita), México DF, Facultad de Ciencias Políticas y Sociales, UNAM.

» McCONNELL, Burt (1939). Mexico at the Bar of Public Opinion. New York, Mail and Express Publishing Company.

» MEYER, Lorenzo (1968). México y los Estados Unidos en el conflicto petrolero, 1917 - 1942, México DF, El Colegio de México.

» MEYERS, Jeffrey (1989). "Evelyn Waugh: Brilliant and Loathsome”. Contemporary Literature, Vol. 30, No. 4, Winter. University of Wisconsin Press, p. 589

» MORGAN, Hugh (1984). The United States Press Coverage of Mexico During the Presidency of Lázaro Cárdenas, Ph.D. Dissertation, Department of History in the Graduate School, Southern Illinois University, Carbondale.

» SILVA HERZOG, Jesús (1993). Una vida en la vida de México y Mis últimas andanzas, 1947 - 1972. México DF, Siglo XXI Editores y El Colegio Nacional.

» VON MENTZ, Brígida, et. al. (1988). Los empresarios alemanes, el Tercer Reich y la oposición de derecha a Cárdenas. México, DF, Centro de Investigación y Estudios Superiores en Antropología Social.

» WAUGH, Evelyn (1999). Robbery Under Law: The Mexican Object-Lesson. N.Y., The Akadine Press, Pleasantville. 